\title{
Erratum to: Shannon Entropy to Evaluate Substitution Rate Variation Among Viral Nucleotide Positions in Datasets of Viral siRNAs
}

\author{
Aysan Ghasemzadeh, Marta Małgorzata ter Haar, \\ Masoud Shams-bakhsh, Walter Pirovano, and Vitantonio Pantaleo
}

\section{Erratum to:}

Chapter 15 in: Vitantonio Pantaleo and Michela Chiumenti (eds.), Viral Metagenomics: Methods and Protocols, Methods in Molecular Biology, vol. 1746, https://doi.org/10.1007/978-1-4939-7683-6_15

The original online version of Chapter 15 was published with incorrect sur name of the author, the sur name should be "ter Haar" instead of "Haar". The online version chapter has been updated. 